\title{
Microhardness of Styrene/Butadiene Block Copolymer Systems: Influence of Molecular Architecture
}

\author{
G. H. Michler, ${ }^{1}$ F. J. Baltá-Calleja, ${ }^{2}$ I. Puente, ${ }^{2}$ M. E. Cagiao, ${ }^{2}$ K. Knoll, ${ }^{3}$ S. Henning, ${ }^{1}$ \\ R. Adhikari ${ }^{1}$ \\ ${ }^{1}$ Department of Engineering, Institute of Materials Science, Martin-Luther-Universität Halle-Wittenberg, D-06099 \\ Halle/Saale, Germany \\ ${ }^{2}$ Instituto de Estructura de la Materia, Consejo Superior de Investigaciones (CSIC), Serrano 119, 28006 Madrid, Spain \\ ${ }^{3}$ BASF Aktiengesellschaft, Polymers Laboratory, ZKT/I-B 1, D-67056 Ludwigshafen, Germany
}

Received 17 December 2002; accepted 5 January 2003

\begin{abstract}
The influence of molecular architecture on the mechanical properties of styrene/butadiene block copolymers was investigated by means of the microhardness technique. It was found that the microhardness of the styrene/butadiene block copolymers is dictated by the nature of microphase separated morphology. In contrast to polymer blends and random copolymers, in which the microhardness generally follows the additivity rule, the behavior of the investigated block copolymers was found to significantly deviate depending on their molecular architecture.
\end{abstract}

The glass-transition temperature of the polystyrene phase $\left(T_{g-P S}\right)$, which practically remained constant and that of the polybutadiene phase $\left(T_{g \text {-PB }}\right)$, which varied with the change in the block copolymer architecture, apparently do not influence the microhardness values of the block copolymers. (C) 2003 Wiley Periodicals, Inc. J Appl Polym Sci 90: 1670-1677, 2003

Key words: block copolymers; microhardness; amorphous polymers; molecular architecture; morphology

\section{INTRODUCTION}

For many practical applications of polymers, a balance of mechanical properties such as toughness, stiffness, and strength is required. Amorphous block copolymers consisting of polystyrene (PS) and polyisoprene (PI) or polybutadiene (PB) units are an example of nanostructured heterogeneous polymers in which the mechanical properties are generally controlled by a microphase separated morphology, that is, adjustable by the block copolymer composition. ${ }^{1}$ Styrene-blockbutadiene-block-styrene (SBS) triblock copolymers, given the widely separated glass-transition temperatures $\left(T_{g}\right)$ of their constituent phases, provide a broad range of service temperatures. Their significance concerning technical applications lies in the

\footnotetext{
Corespondence to: G. Michler (michler@iw.uni-halle.de).

Contract grant sponsor: Deutsche Forschungsgemeinschaft.

Contract grant sponsor: Kultusministerium des Landes Sachsen-Anhalt.

Contract grant sponsor: MCYT, Spain; contract grant numbers: BFM 2000-1474 and HA 2000-0070.

Contract grant sponsor: Deutscher Akademischer Austauschdienst (DAAD).

Contract grant sponsor: Alexander von Humboldt-Stiftung.

Contract grant sponsor: Dirección General de Universidades, Ministerio de Educación, Spain.
}

Journal of Applied Polymer Science, Vol. 90, 1670-1677 (2003) (C) 2003 Wiley Periodicals, Inc. fact that, at room temperature, the flexible rubbery blocks $\left(T_{g} \sim-100^{\circ} \mathrm{C}\right)$ are anchored on both sides by the glassy chain ends $\left(T_{g} \sim+100^{\circ} \mathrm{C}\right)$. Therefore, these block copolymers behave as a crosslinked rubber at ambient temperature and allow a thermoplastic processing at higher temperature. ${ }^{1}$

The microindentation hardness technique has found in recent years widespread applications in polymer research. ${ }^{2}$ The technique has been increasingly used in the characterization of the homopolymers, polymer blends, and copolymers. A very attractive feature of this technique is its ability for the micromechanical characterization of the polymeric materials. In addition, microhardness may be successfully used to gain information on the morphology-mechanical property correlations in heterophase systems. Because this technique is on one hand relatively simple and on the other hand very sensitive to the phase behavior of the heterogeneous systems, it may serve as an important tool to gain a straightforward and deeper insight into the microstructure-morphology correlation. ${ }^{2,3}$ In the past, semicrystalline aliphatic polymers such as polypropylene (PP), polyethylene (PE), and condensation polymers have been extensively investigated. In particular the technique was used to assess straininduced polymorphic transitions in semicrystalline polymers. ${ }^{4}$

In recent years, the phase behavior of the styrene/ diene diblock copolymers and their orientation behavior attributed to mechanical loading have been exten- 
TABLE I

Characteristic Data of the Block Copolymers Studied ${ }^{20}$

\begin{tabular}{|c|c|c|c|c|}
\hline Sample & $M_{n}(\mathrm{~g} / \mathrm{mol})^{\mathrm{a}}$ & $M_{w} / M_{n}{ }^{\mathrm{a}}$ & $\Phi_{\mathrm{ST}}^{\mathrm{b}}(\%)$ & Molecular architecture \\
\hline LN1-S74 & 82,000 & 1.07 & 74 & SBS triblock with symmetric end blocks \\
\hline LN2-S74 & 93,000 & 1.13 & 74 & $\begin{array}{l}\text { Asymmetric triblock having a center PB block } \\
\text { with tapered block transition to the long PS } \\
\text { end block }\end{array}$ \\
\hline LN4-S65 & 116,000 & 1.20 & 65 & Triblock containing an PS-co-PB midblock \\
\hline ST1-S74 & 91,800 & 1.99 & 74 & $\begin{array}{l}\text { Highly asymmetric neat star block with SB } \\
\text { arm structure, PB core }\end{array}$ \\
\hline ST2-S74 & 109,200 & 1.69 & 74 & $\begin{array}{l}\text { Highly asymmetric tapered star block with } \\
\text { SBS arm structure, PS core }\end{array}$ \\
\hline
\end{tabular}

a Determined by gel permeation chromatography (GPC) using PS calibration.
b Total styrene volume fraction determined by Wijs double-bond titration.

sively studied. ${ }^{5-7}$ Many studies report the deformation mechanisms of block copolymers as a function of microphase separated morphology and the orientation of the microdomains relative to the strain direction. ${ }^{8-13}$ In earlier studies, we examined the influence of the macromolecular architecture on the morphology formation, phase behavior, and deformation mechanism of styrene/butadiene block copolymers. ${ }^{14-16}$ However, there are nearly no systematic studies of the micromechanical behavior of the amorphous polymers such as SBS triblock copolymers, particularly in correlation with their molecular architecture.

The aim of this contribution was to study the correlations between the molecular architecture, the microhardness, and the macroscopic mechanical properties of selected styrene/butadiene block copolymers.

\section{EXPERIMENTAL}

\section{Materials and sample preparation}

The characteristic data of the investigated block copolymers are listed in Table I. These materials possess a nearly identical net chemical composition (styrene volume fraction $\sim 0.70$ ) but differ in the chain architecture; the symbols S65 and S74 give the PS volume content. The specimens were prepared by injection molding and extrusion.

The block copolymers were synthesized by the secbutyl lithium (sBuLi)-initiated sequential living anionic polymerization. To get the asymmetric block copolymer (i.e., copolymers having styrene terminal blocks of unequal lengths), a different amount of styrene monomers was polymerized as the first and the last blocks of the chain. The tapered block transition was incorporated by allowing a mixture of styrene and butadiene monomers to polymerize simultaneously. Asymmetric star block copolymers were obtained by allowing the living linear chains of different overall lengths to couple by oligofunctional coupling agents. The synthesis of the block copolymers of the types used in this study may be found elsewhere. ${ }^{17-19}$ The phase behavior and morphology of the block copolymers used in this study were previously discussed in detail. ${ }^{14-16,20}$

\section{Techniques}

Tensile testing was performed at room temperature $\left(23^{\circ} \mathrm{C}\right)$ using a universal tensile machine (Zwick 1425; Germany) at a crosshead speed of $50 \mathrm{~mm} / \mathrm{min}$ using extruded samples according to ISO 527. At least 10 samples were tested in each case. The Young's modulus $(E)$ and yield stress $\left(\sigma_{y}\right)$ were calculated by evaluation of the initial slope and from the first maximum of the corresponding stress-strain curves, respectively.

Differential scanning calorimetric (DSC) measurements were performed with a Mettler DSC 820 in the temperature range from -120 to $+150^{\circ} \mathrm{C}$ at a rate of $10^{\circ} \mathrm{C} / \mathrm{min}$ using the cycle heating-cooling-heating. The heat flow and the second derivative of the heating scans were used for the analysis of the glass-transition temperature. The weight of the investigated sample was about $10 \mathrm{mg}$.

Microindentation hardness $(H)$ was calculated by measuring the residual impression produced by a Vickers diamond indenter onto the surface of the injection-molded tensile bars. For the sake of comparison, the measurements were made on the specimen surface in the middle of the injection-molded bars. An indentation time of $6 \mathrm{~s}$ and a load of $50 \mathrm{~g}$ were used. For the sample LN4 loads of 10 and $15 \mathrm{~g}$ were applied. The Vickers hardness is defined $a s^{2}$ :

$$
H=k \frac{P}{d^{2}}
$$

where $P$ is the applied load (in $\mathrm{N}$ ), $d$ is the diagonal of the impression (in $\mathrm{m}$ ), and $k$ is a geometric factor (=1.854). The $H$ values were derived from an average 
of at least 10 indentations. The indentation anisotropy can be determined from the equation

$$
\Delta H=\frac{H_{\|}-H_{\perp}}{H_{\|}}=1-\left(\frac{d_{\|}}{d_{\perp}}\right)^{2}
$$

where $d_{\|}$and $d_{\perp}$ are the diagonals of impressions parallel and perpendicular to the orientation direction, respectively. Unless otherwise stated, in this work we use the hardness calculated from $d_{\perp}$.

\section{MOLECULAR STRUCTURE AND PHASE BEHAVIOR}

The microstructure of the block copolymers used was analyzed in our preceding studies using scanning force microscopy (SFM) and transmission electron microscopy (TEM). ${ }^{14,16,20,21}$ The molecular architecture and the morphology of the samples as revealed by the microscopic techniques are schematically represented in Figure 1. All block copolymers have identical chemical composition (74 vol \% polystyrene) except for LN4, which contains a total styrene volume content of $65 \%$. Despite having nearly identical chemical composition, these block copolymers possess a wide variety of morphologies as a consequence of modification of the molecular architecture.

Sample LN1-S74 has a simple symmetric linear architecture (symmetric outer polystyrene, PS blocks) held apart by a pure butadiene (PB) block having a sharp interface with the neighboring polystyrene blocks. This sample, having a composition of $74 \mathrm{vol} \%$ polystyrene, exhibits hexagonal PB cylinders dispersed in the PS matrix, as expected from the classical picture of morphology formation in block copolymers. $^{5}$

\begin{tabular}{lll}
\hline Sample & Molecular structure & Morphology \\
\hline LN1-S74 & & \\
ST1-S74 & &
\end{tabular}

Figure 1 Molecular structure and morphology of the block copolymer studied (schematic); white and dark areas represent hard and soft phases, respectively.
TABLE II

Glass-Transition Temperature of the Soft and Hard Phases in the Investigated Block Copolymers (DSC)

\begin{tabular}{lccc}
\hline & $\begin{array}{c}T_{g-\mathrm{PB}} \\
\text { (soft phase }) \\
\left({ }^{\circ} \mathrm{C}\right)\end{array}$ & $\begin{array}{c}T_{g-\text { PS }} \\
\text { (hard phase } \\
\left({ }^{\circ} \mathrm{C}\right)\end{array}$ & $H(\mathrm{MPa})$ \\
\hline LN1-S74 & -95 & 97 & 72 \\
LN2-S74 & -53 & 101 & 39 \\
LN4-S65 & -34 & $\sim 70$ & 8 \\
ST1-S74 & -81 & 104 & 52 \\
ST2-S74 & -79 & 104 & 44 \\
Pure PS & - & - & 177 \\
\hline
\end{tabular}

The linear block copolymers LN2 and LN4 have a modified molecular architecture, leading to a significant deviation in the microphase morphology expected from the classical block copolymer phase diagram. Because of the presence of a tapered transition and an asymmetric structure of the outer polystyrene blocks, the linear block copolymer LN2-S74 (74 vol \% styrene) presents a lamellar morphology instead of a cylindrical one. ${ }^{14}$

In the case of LN4-S65 (65\% of polystyrene), formation of dispersed PS domains within the matrix of the rubbery phase (random styrene/butadiene copolymer, PS-co-PB) takes place because of the presence of a homogeneous PS-co-PB phase as the matrix, which forms about $68 \mathrm{vol} \%$ of the copolymer molecule. The diffuse boundary between the domains and the matrix as well as the absence of a well-ordered morphology (e.g., predominantly hexagonal array of PS cylinders) place this complex morphology close to the orderdisorder transition (ODT). ${ }^{17}$

The influence of the modified architecture of the block copolymers is also reflected in the shift of the glass-transition temperature $\left(T_{g}\right)$ of the butadiene phase $\left(T_{g-\mathrm{PB}}\right)$ (Table II). The $T_{g}$ values of polystyrene $\left(T_{g \text {-PS }}\right)$ and polybutadiene $\left(T_{g-\mathrm{PB}}\right)$ blocks in LN1 at about -95 and $+97^{\circ} \mathrm{C}$, respectively, nearly correspond to the glass-transition temperatures of the corresponding homopolymers. The $T_{g \text { - } \mathrm{PB}}$ values for the other samples increase according to the following sequence: LN1-LN2-LN4. Likewise, the $T_{g-\mathrm{PB}}$ values in the star block copolymers are shifted toward higher temperatures $\left(\sim-80^{\circ} \mathrm{C}\right)$. Except for the sample $\mathrm{LN} 4$, the $T_{g \text {-PS }}$ values remain almost unchanged.

The $T_{g}$ increase of polybutadiene is indicative of the presence of styrene units in the butadiene phase, which hinder the mobility of the flexible PB chains. Therefore, the $T_{g-\mathrm{PB}}$ increase for the linear block copolymers LN2 and LN4 suggests a deviation of the apparent phase volume fraction from the actual phase ratio of the copolymers. The same explanation is valid for the star block copolymers (ST1 and ST2), where additional effects of highly asymmetric architecture and star topology have to be taken into account. Be- 


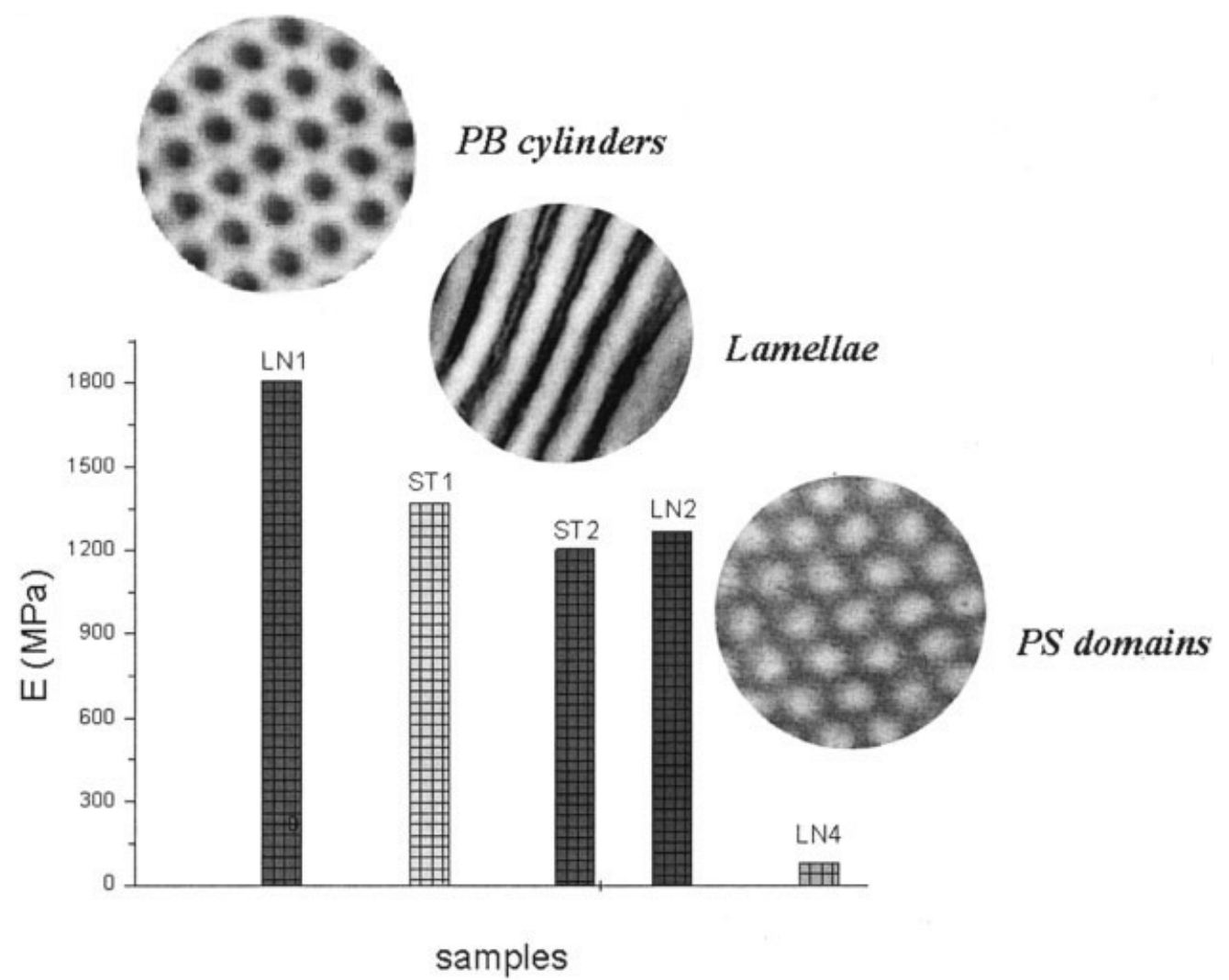

Figure 2 Correlation between microphase separated morphology and elastic modulus $(E)$.

cause the styrene content in the middle rubbery block increases in the sequence LN1 $\rightarrow$ LN2 $\rightarrow$ LN4, the compatibility of the outer PS chains (i.e., the ease of phase mixing) also increases in the same manner. Hence it may be expected that the width of the interface would increase according to the sequence: LN1 $\rightarrow$ LN2 $\rightarrow$ LN4. Similarly, the interface width for the star block copolymers ST1 and ST2 would lie between that for the linear block copolymers LN1 and LN4. Nevertheless, a quantitative estimation of the interface thickness cannot be made on the basis of the results obtained so far.

In the case of sample LN4-S65 the $T_{g \text {-PS }}$ value decreases with reference to the glass transition of the PS homopolymer $\left(100-106^{\circ} \mathrm{C}\right)$. It should be noted that the polystyrene chains in this sample have a molecular weight of about $18,000 \mathrm{~g} / \mathrm{mol}$, which according to Fox ${ }^{22}$ yields a glass-transition temperature of about $95^{\circ} \mathrm{C}$ :

$$
T_{g}=106^{\circ} \mathrm{C}-\frac{2.1 \times 10^{5}}{M_{n}}
$$

where $T_{g}$ is the glass-transition temperature of polystyrene having a number-average molecular weight of $M_{n}$. The measured $T_{g-\mathrm{PS}}$ in this block copolymer $\left(\sim 70^{\circ} \mathrm{C}\right.$; see Table II) is about $25^{\circ} \mathrm{C}$ lower than the value estimated from eq. (3). This deviation in $T_{g \text {-PS }}$ suggests that the polystyrene phase exists predominantly as a mixed phase. This mixing leads to the weak segregation behavior of the block copolymer, thereby hindering the formation of a well-ordered morphology.

The obtained results demonstrate that a modification in molecular architecture leads to a significant shift in the phase behavior and morphology formation of the block copolymers. In general, the apparent volume fraction of the soft phase increases as a result of the incorporation of PS chains into the PB phase, leading as a consequence to a $T_{g-\mathrm{PB}}$ increase.

\section{RESULTS AND DISCUSSION}

\section{Morphology-microhardness correlation}

According to the elastic modulus $(E)$ values obtained for the block copolymers (see Fig. 2) these systems may be grouped into three categories.

1. One sample having an $E$ value of about $1800 \mathrm{MPa}$ (PS matrix: LN1).

2. Three samples with $E$ values in the range of 1200 MPa (lamellar structure: LN2, ST1, and ST2).

3. One sample having the Young's modulus of about $30 \mathrm{MPa}$ (rubbery matrix: LN4).

This is a direct indication that the mechanical behavior of the block copolymers is dictated, in general, by the 


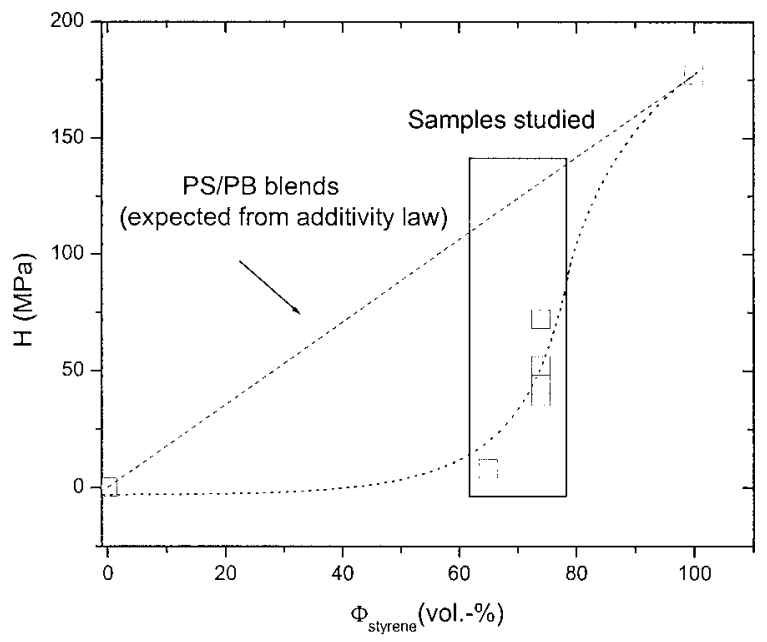

Figure 3 Plot of microhardness $(H)$ as a function of block copolymer composition.

nature of the microphase separated morphology irrespective of the block copolymers architecture and net chemical composition.

In our samples, one of the phases (i.e., PB) has a glass-transition temperature far below the room temperature. Thus it may be regarded as a liquidlike phase whose hardness value can be assumed to be negligible. Figure 3 shows the plot of the microhardness of the samples as a function of total styrene content. The dotted straight line illustrates the hardness as a function of composition according to the additivity law ${ }^{2}$ :

$$
H=H_{\mathrm{PS}} \Phi_{\mathrm{PS}}+H_{\mathrm{PB}}\left(1-\Phi_{\mathrm{PS}}\right)
$$

where $H_{X}$ and $\Phi_{X}$ represent the microhardness and the weight fraction of the component $X$, respectively. The obtained results show a large deviation of $H$ data from the additivity law, the hardness values of the block copolymers extending over a wide range in spite of the nearly identical net chemical composition. Similar to the Young's modulus-structure correlation obtained (see Fig. 2), the block copolymer samples show three different ranges for the $H$ values depending on the type of microphase separated morphology:

1. Sample LN1 showing greatest hardness $(H=72$ $\mathrm{MPa})$.

2. Samples ST1, ST2, and LN2 having an intermediate average hardness $(H=45 \mathrm{MPa})$.

3. Sample LN4 with the lowest hardness $(H=8$ $\mathrm{MPa})$.

Deviations from the additivity law have been also shown to occur in the rubber-modified semicrystalline polymers (iPP) in which the hardness of the crystals in the blends is lower than that in the homopolymer. ${ }^{23}$
However, the deviation in the $H$ values observed in the present study is significantly larger than that observed in other polymer materials. The larger deviations detected in our case indicate that the total styrene content present in the microphase separated block copolymers has no correlation with the microhardness data. Apparently in this case the nature of the microphase separated morphology plays a decisive role.

In addition, the $H$ values of Figure 3 show a decrease as a function of increasing $T_{g-\mathrm{PB}}$ (see Fig. 4). Because the $T_{g-\mathrm{PB}}$ is much lower than the test temperature, the hardness of the soft phase can be assumed to be negligible (i.e., the variation of $T_{g \text {-PB }}$ should not have any influence on the hardness of the copolymers). Comparison of Figures 3 and 4 leads us to the following conclusions: going from sample LN1 to the group LN2, ST1, ST2 and to the sample LN4 there is an increasing amount of PS molecules in the PB phase. This gives rise to an increase of the apparent soft phase and, therefore, to the change of PB domains into PB lamellar and PB matrix. Following the same sequence one observes a hardness decrease and a shift of $T_{g \text {-PB }}$ to higher temperatures.

The low $H$ values for the block copolymers can be attributed to the extensive plastic deformation under the indenter. In diblock copolymers, a lamellar structure is expected for a symmetric composition. However, the $H$-values for the investigated lamellar block copolymers, which have an overall $74 \%$ volume fraction of polystyrene each, are even smaller than the $H$ value that may be expected for a symmetric composition (i.e., 50\% PS). The reason is the presence of several local energy-absorbing phenomena such as shearing in the rubbery layers, rotation, twisting and drawing of lamellae, which contribute to reduce the yield stress, thus yielding as a consequence low $H$-values.

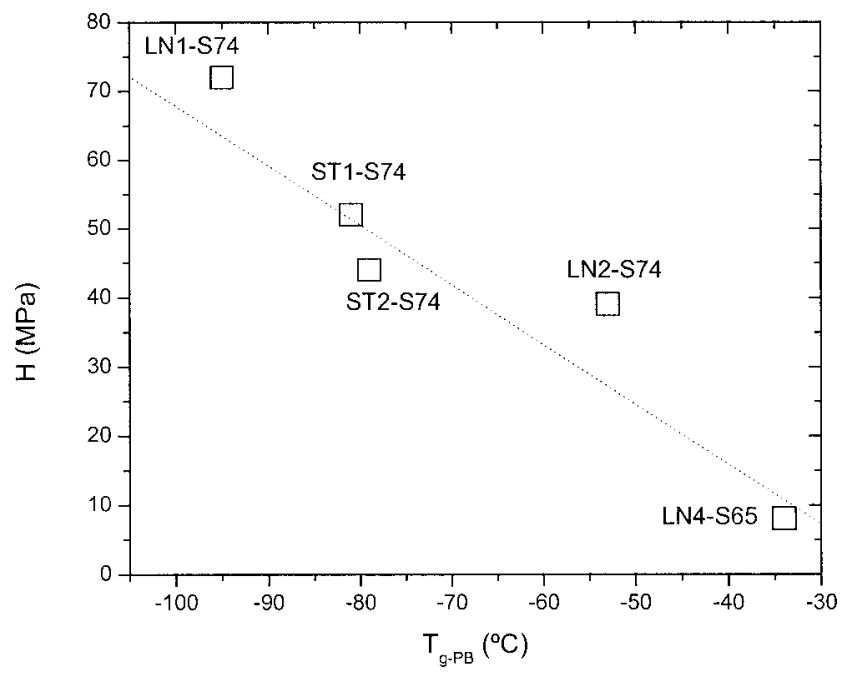

Figure 4 Plot of microhardness $(H)$ as a function of $T_{g-\mathrm{PB}}$ for the block copolymers. 


\section{Correlation of microhardness to macroscopic mechanical properties}

The penetration of the sharp indenter on the sample surface results in a permanent irreversible plastic deformation (i.e., it is related to the yielding of the poly$m^{2}{ }^{2}$ ). According to the theory of plasticity, the hardness value for a Vickers indenter is approximately equal to three times the yield stress in frictionless compression. It was shown by Baltá-Calleja et al. that, for a wide variety of polyethylene samples, ${ }^{2,24}$ the ratio $H / \sigma_{y}$ was close to 3 , where $\sigma_{y}$ is the yield stress in tension. A deviation from this value may occur if the rate of indentation and the rate of deformation from the tensile test deviate from each other. Higher strain rates in the tensile test lead to an increase in yield stress, thus inducing the ratio $\mathrm{H} / \sigma_{y}$ to decrease. For rubber-modified iPP samples strained at a crosshead speed of $10 \mathrm{~mm} / \mathrm{min}$, the ratio was found to be 2.7. ${ }^{23}$

Figure 5 illustrates the plots of hardness of the samples as a function of yield stress (a) and Young's modulus (b), respectively. The first-order linear regression fitting of the available data gives a slope $H / \sigma_{y}=1.9$ for the former, which is smaller than the value mentioned in the literature. This discrepancy may be attributed to the higher strain rate used in the tensile testing. It should be further pointed out that a few data points do not satisfactorily fit into the straight line. This behavior might also be a result of different extent of orientation of the microstructure in the injection-molded samples studied. The shear stress of the injection-molding process would cause the orientation of the microphase separated structures. However, depending on the molecular architecture and resulting morphology of the block copolymers, the phase separated structures might have a different extent of orientation. It is known that the tensile yield stress of the block copolymers is strongly influenced by the orientation of the microdomains. $8,9,25,26$

The plot $H$ versus $E$ yields a linear relationship [Fig. $5(\mathrm{~b})]$. The linearity of the experimental results is similar to the results for $\mathrm{PE}^{24}$ and Struik's prediction for other polymers. ${ }^{27}$ However, the experimental value of $E / H=28$ measured in the block copolymers is appreciably larger than that obtained by Struik ${ }^{27}$ and Flores et al. ${ }^{24}$

\section{Influence of processing}

Although polymeric materials possess a rich variety of structural diversities, not all the structural or morphological details influence the ultimate mechanical properties to the same extent. There are details that play a dominant role in determining their properties (i.e., the so-called properties-determining structures ${ }^{28}$ ). In block copolymers, these are primarily the microphase

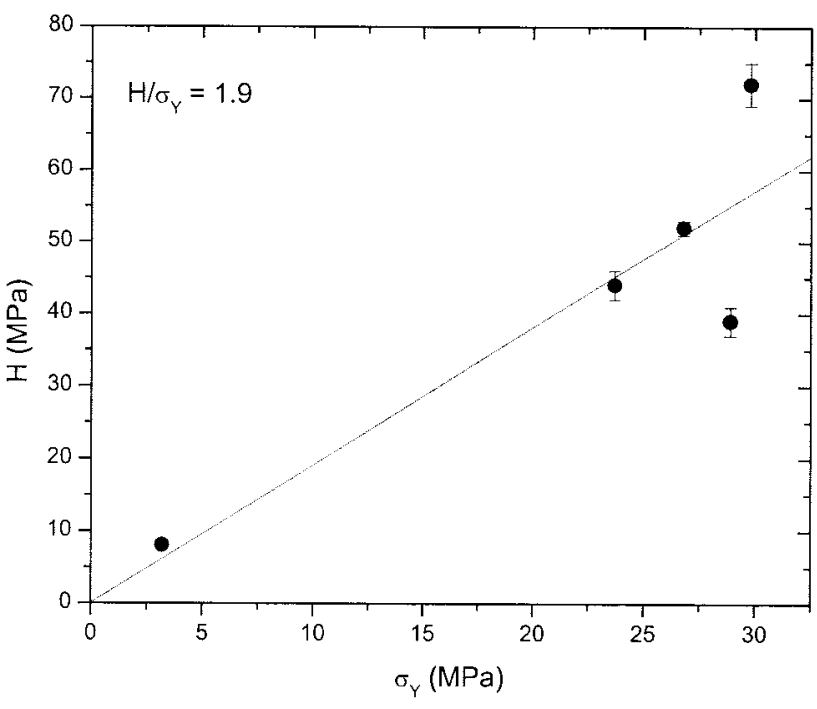

(a)

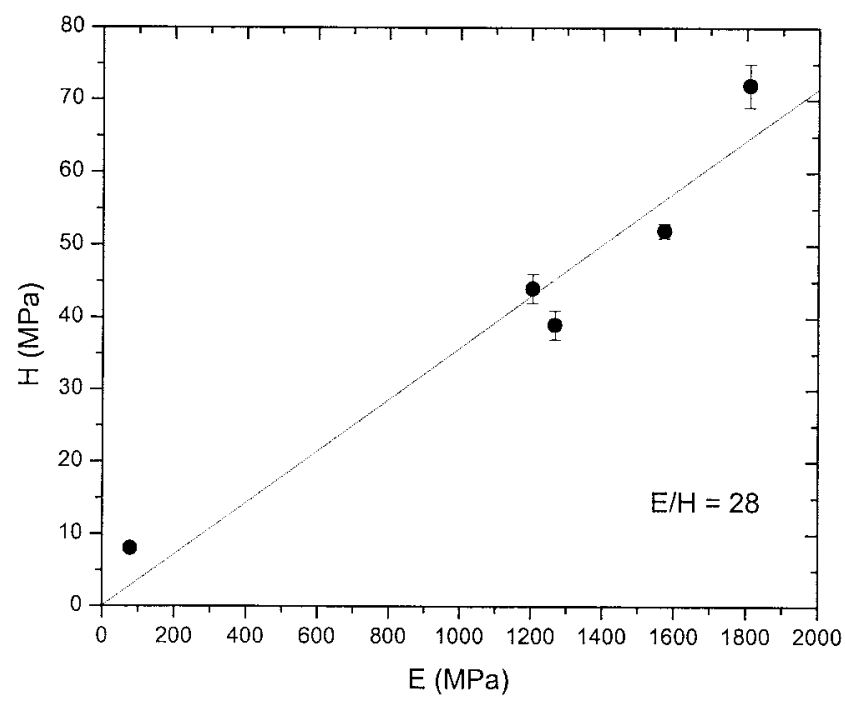

(b)

Figure 5 (a) $H$ versus $\sigma_{y}$ and (b) $H$ versus $E$ for the investigated block copolymers.

separated morphologies. The arrangement (e.g., the orientation) and even the nature of these structures may be greatly influenced by the processing conditions. 8,9,25,26,29 Accordingly the mechanical behavior of the block copolymers may vary. The influence of an external mechanical field (e.g., shearing) results in the orientation of the microdomain structures. Such an orientation introduces a pronounced anisotropy in their mechanical properties. Entirely different values of yield stress and Young's modulus may be obtained on loading the oriented block copolymers parallel and perpendicular to the orientation direction. ${ }^{26,29}$

Subjecting the oriented SBS triblock copolymers with PS cylinders in the PB matrix to undergo tensile deformation and using composite theories, Odell and 


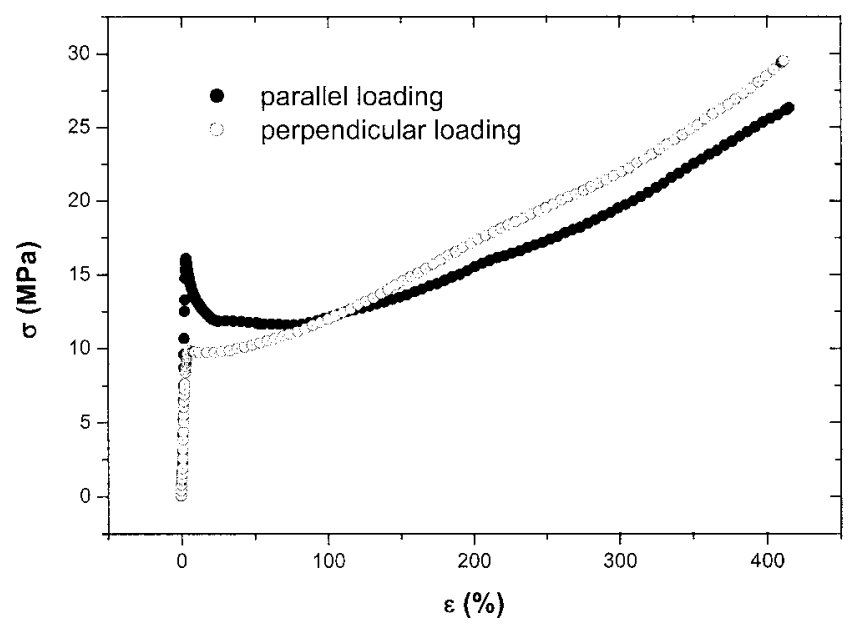

Figure 6 Stress-strain curve of an oriented lamellar block copolymer, LN2 (extrudate loaded parallel and perpendicular to the extrusion direction, loaded at $23^{\circ} \mathrm{C}$ at a crosshead speed of $50 \mathrm{~mm} / \mathrm{min}$ ); the tensile bar had a total length of about $80 \mathrm{~mm}$ and sample had a thickness of about $0.5 \mathrm{~mm}$.

Keller $^{29}$ demonstrated that the elastic modulus of these block copolymers obtained by loading them parallel to the cylinder axis could be several times higher than those obtained by loading the block copolymers perpendicularly to the cylinder orientation direction.

The stress-strain curves of the sample LN2 prepared by extrusion (see Fig. 6) illustrate the influence of the orientation of morphology on the mechanical behavior of the block copolymers. This sample has a lamellar structure (Fig. 1) and, in the extruded sheet, the microphase separated structures are predominantly oriented in the extrusion direction. ${ }^{26}$

The processing of the block copolymers by injection molding also provides a similar kind of shear field. The shear forces acting on the surface of the sample during processing are different from those acting in the center of the bar. The shear forces at the surface are larger than inside and decrease along the cross section, reaching a minimum in the middle. Therefore, the structure of the block copolymers (domain orientation) in extrudates and moldings may change along the specimen cross section.

Considering the anisotropy of the mechanical behavior in the moldings, one may differentiate between two different processes:

1. The anisotropy arising from the different mechanical behavior parallel and perpendicular to the domain orientation direction at a particular location (e.g., in the middle of the molding bars).

2. The anisotropy arising from different domain orientations across the mold thickness.

In this connection, the occurrence of a pronounced indentation anisotropy of the block copolymers (espe- cially that of lamellar block copolymers; see Fig. 1) is thus not surprising. Such an indentation anisotropy may not be expected in the sample prepared by solution casting and subsequently annealing for $48 \mathrm{~h}$ in vacuum above the glass-transition temperature of the polystyrene phase (results are not presented here). For example, the microhardness of the sample LN2 parallel and perpendicular to the injection direction was found to be 43 and $39 \mathrm{MPa}$, respectively. The higher value of $H$ parallel to the injection direction is an indication of the domain molecular orientation coupled with a preferential local elastic recovery of these rigid structures.

The microhardness technique has been successfully used to detect the local degree of molecular orientation in injection-molded samples ${ }^{2}$ including amorphous polymers. ${ }^{30}$

We have examined the microindentation behavior of one of the block copolymer (LN2-S74) samples prepared by injection molding across the molding thickness $(4 \mathrm{~mm})$ of the sample. The sample for microhardness testing was prepared by microtoming the middle of the bar. Indentations were made on the microtomed surface in the direction perpendicular to the injection direction.

In all cases an indentation anisotropy arises because the microhardness is maximum when the indentation diagonal is parallel to the orientation direction and minimum when the diagonal is normal to it. The larger $H_{\|}$value corresponds to an instant elastic recovery of the domains in the injection direction after load release. The low $H_{\perp}$ value is ascribed to the plastic deformation of the domains under shear.

Figure 7(a) illustrates the variation of $H$ (measured by $d_{\perp}$, the indentation diagonal perpendicular, and $d_{\|}$, the indentation diagonal parallel to the injection direction) across the sample thickness. The results clearly show that the $H$-value monotonically decreases from the surface to the interior, reaching a minimum at the center of the mold.

The variation of the $H$-values can be correlated to the shear-induced orientation of the molecules and the microphases.

Assuming the parabolic profile of shear force in the injection-molded bars, a similar profile of the shearinduced orientation of the block copolymer domains and macromolecules may be expected in which the hardness values follow a similar profile.

Figure 7(b) illustrates the plot of indentation anisotropy across the sample thickness. This plot especially illustrates the remarkable variation in the molecular orientation through the sample cross section.

\section{CONCLUSIONS}

- The microhardness behavior of the styrene/butadiene block copolymers deviates from the additivity law of individual components. 


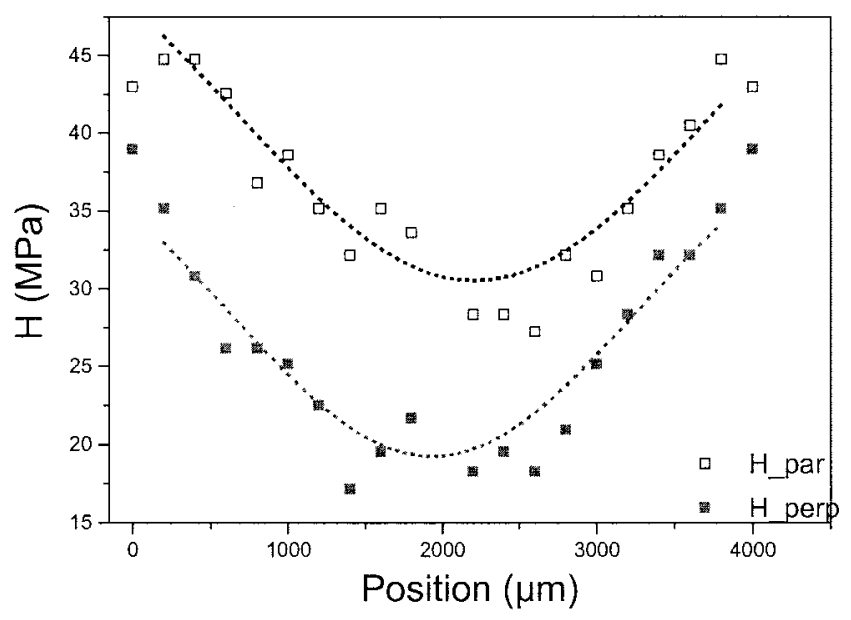

(a)

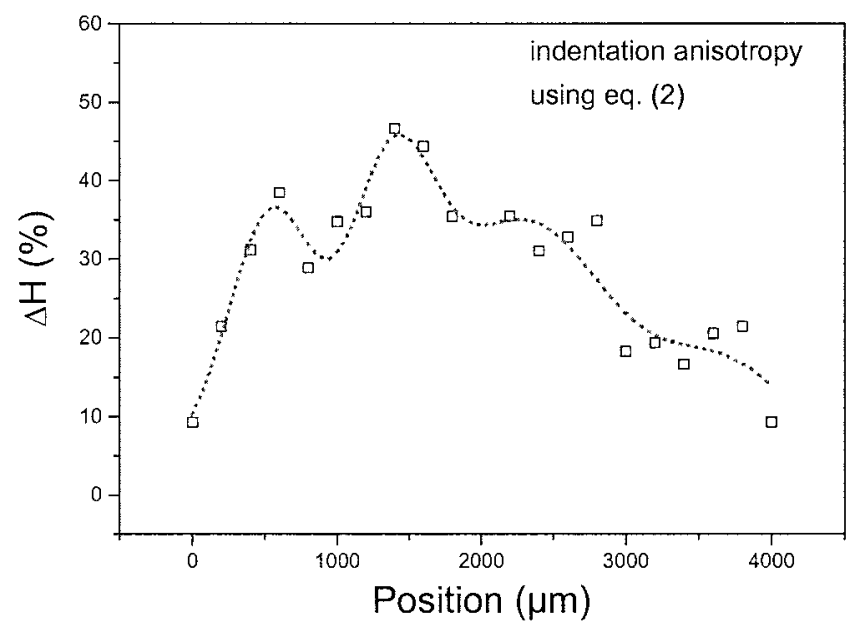

(b)

Figure 7 (a) Microhardness, parallel $H_{\|}$and perpendicular $H_{\perp}$ to the loading direction versus distance across the thickness of the injection mold of a lamellar block copolymer (LN2); (b) indentation anisotropy measured in the sample LN2.

- The microhardness is determined primarily by the nature of the microphase separated morphology.

- The glass-transition temperature of the soft liquidlike phase does not influence the microhardness behavior.

- The injection-molded block copolymer samples show a pronounced anisotropic behavior across the thickness cross section. In addition, a remarkable variation in molecular orientation is found.

We thank the Deutsche Forschungsgemeinschaft and the Kultusministerium des Landes Sachsen-Anhalt and MCYT, Spain (Grants BFM 2000-1474 and HA 2000-0070) for the support of this work. The financial support from the Deutscher Akademischer Austauschdienst (DAAD) and from the Alexander von Humboldt-Stiftung is gratefully acknowledged. One of us (G.H.M.) thanks the Dirección General de
Universidades, Ministerio de Educación, Spain, for the award of the Humboldt-Mutis Prize.

\section{References}

1. Holden, G. Understanding Thermoplastic Elastomers; Carl Hanser Verlag: Munich, 2000.

2. Baltá-Calleja, F. J.; Fakirov, S. Microhardness of Polymers; Cambridge University Press: Cambridge, UK, 2000.

3. Baltá-Calleja, F. J.; Fakirov, S. In: Structure-Microhardness Correlations in Condensation Copolymers; Baltá-Calleja, F. J., Roslaniec, Z., Eds.; Block Copolymers; Marcel Dekker: New York, 2000; p. 179.

4. Krumova, M.; Karger-Kocsis, J.; Baltá-Calleja, F. J.; Fakirov, S. J Mater Sci 1999, 34, 2371

5. Hamley: I. W. The Physics of Block Copolymers; Oxford Science Publications: Oxford, UK, 1998.

6. Hasegawa, H.; Hashimoto, T. In: Comprehensive Polymer Science, Suppl. 2; Aggarwal, S. L., Russo, S., Eds.; Pergamon: London, 1996; p. 497.

7. Thomas, E. L.; Lescanec, R. L. In: Self-Order and Form in Polymeric Materials; Keller, A.; Warner, M.; Windle, A. H., Eds.; Chapman \& Hall: London, 1995; p. 147.

8. Cohen, Y.; Albalak, R. J.; Dair, B. J.; Capel, M. S.; Thomas, E. L. Macromolecules 2000, 33, 6502.

9. Honeker, C. C.; Thomas, E. L. Macromolecules 2000, 39, 9407.

10. Schwier, C. E.; Argon, A .S.; Cohen, R. E. Polymer 1985, 26, 1985.

11. Weidisch, R.; Michler, G. H. In: Block Copolymers; Baltá-Calleja, F. J.; Roslaniec, Z., Eds.; Marcel Dekker: New York, 2000; p. 215.

12. Sakurai, S.; Aida, S.; Okamoto, S.; Ono, T.; Imaizumi, K.; Nomura, S. Macromolecules 2001, 34, 3672.

13. Aida, S.; Sakurai, S.; Nomura, S. Polymer 2002, 43, 2881.

14. Adhikari, R.; Godehardt, R.; Lebek, W.; Weidisch, R.; Michler, G. H.; Knoll, K. J Macromol Sci: Phys 2001, 40, 833.

15. Adhikari, R.; Michler, G. H.; Huy, T. A.; Ivankova, E.; Godehardt, R.; Lebek, W.; Knoll, K. Macromol Chem Phys 2003, 204, 488.

16. Michler, G. H.; Adhikari, R.; Lebek, W.; Goerlitz, S.; Weidisch, R.; Knoll, K. J Appl Polym Sci 2002, 85, 683.

17. Knoll, K.; Niessner, N. Macromol Symp 1998, 132, 231

18. Knoll, K.; Niessner, N.; Wunsch, J.; Gausepohl, H. U.S. Pat. 6,369,160, 2002.

19. Trepka, W. J.; Moczygemba, G. A.; Stacy, N. E.; Farrar, R. C. U.S. Pat. 6,265,484, 2001.

20. Adhikari, R. Ph.D. Thesis, Universität Halle-Wittenberg Germany, 2001

21. Adhikari, R.; Michler, G. H. Knoll, K. Macromol Symp, to appear.

22. Equation adapted from: Sperling, L. H. Introduction to Physical Polymer Science, 3rd ed.; Wiley Interscience: New York, 2001; p. 337.

23. Flores, A.; Baltá-Calleja, F. J.; Aurrekoetxea, J.; Gensler, R.; Kausch, H. H. Colloid Polym Sci 1998, 276, 786.

24. Flores, A.; Baltá-Calleja, F. J.; Attenburrow, G. H.; Bassett, D. C. Polymer 2000, 41, 5431.

25. Dair, B. J.; Avgeropoulos, A.; Hadjichristidis, N.; Thomas, E. L. J Mater Sci 2000, 35, 5207.

26. Buschnakowski, M. Master's Thesis, Universität Halle-Wittenberg, 2001.

27. Struik, L. C. E. J Non-Cryst Solids 1991, 395, 131

28. Michler, G. H. In: Polymeric Materials Encyclopedia-Synthesis, Properties and Applications; Salamone, J. S., Ed.; CRC Press: New York, 1996.

29. Keller, A.; Odell, J. A. In: Processing, Structure and Properties of Block Copolymers; Folkes, M. J., Ed.; Elsevier Applied Science: London, 1985; Chapter 2, p. 29.

30. García Gutiérrez, M. C.; Kühnert, I.; Mennig, G.; Rueda, D. R.; Baltá-Calleja, F. J. J Mater Sci Lett 1999, 18, 1237. 